\title{
Returns to handedness in professional hockey
}

\author{
Dennis Coates $^{\dagger}$ and Sara Azmoudeh Fard
}

October 2011

\begin{abstract}
Research in economics has examined many determinants of earnings, including whether an individual is left or right handed. In the soccer labor market, being able to kick well with both the left and the right foot is rewarded with a salary premium. This paper examines pay and performance for hockey players that shoot left-handed versus those that shoot right handed. We find that after controlling for points, time on the ice, player size and age, and team and season, players are paid differently by position, and players playing the same position may be paid differently because they shoot left versus right handed. Moreover, points scored are compensated differently for left handed shooting players on the right wing than for other players. These results suggest a hockey player labor market inefficiency.
\end{abstract}

\section{JEL Classification Codes: L83}

Keywords: Sports, labor market inefficiencies, hockey, NHL

The authors wish to thank Joe McGarrity and Bernd Frick for comments on an earlier draft of this paper.

Paper prepared for the International Atlantic Economic Society meetings, October 20-23, 2011, Washington, DC.

\footnotetext{
†Department of Economics, University of Maryland, Baltimore County, 1000 Hilltop
} Circle, Baltimore, MD 21250, (410) 455-3243 (office), coates@umbc.edu 
Labor economists have studied the determinants of earnings for a very long time, with natural emphasis on the influence of experience and education. Empirical analysis of wages and earnings has also focused on racial and gender differences in compensation. (See Altonji and Blank, 1999, for a review.) In recent years, analysis has extended to the role of appearance, with better looking (Biddle and Hamermesh, 1994) and taller (Heineck, 2005) Individuals being more highly paid than less attractive and shorter people. Denny and O'Sullivan (2007) and Reubeck, Harrington, Jr., and Moffitt (2007) considered the role of handedness in earnings determination. Denny and O'Sullivan (2007) find a premium for left-handed males, with the boost a bit larger for manual laborers, but there is a similarly sized penalty for left-handed females. By contrast, Reubeck, et al. (2007), find that college educated, left handed males earn about $15 \%$ more than college educated right handed males.

Both Denny and O’Sullivan (2007) and Reubeck, et al. (2007) examine the extensive literature on differences between right and left handed individuals. See their discussion for details, but they each cite evidence on intelligence and creativity as well as differences in rates of autism and learning disabilities. Explanations for the differences between left and right handed individuals run from cognitive to environmental. For example, some evidence suggests that lefthanded children make up a disproportionate share of those in the 0.01 percent of students taking the SAT exam at age 13 (Benbow, 1986). Hicks and Dusek (1980) find a lower prevalence of right-handedness among gifted (IQ greater than 131) children. Annett and Manning (1989) find that those with stronger tendencies toward right-handedness scored worse on intelligence tests, and tests of other abilities including language. Left-handers face an environment many parts of which are designed for right handed people. This may be the reason researchers find that left 
handers appear to be more accident prone or clumsy than right handed people. Facing this world, left handed people may compensate for the situation by working harder to develop skills to cope with their environment than do right handed individuals, and the result may be better human capital.

Based on their reading of the psychology and neurology literatures, Denny and O’Sullivan (2007) propose three hypotheses related to compensation and handedness. The hypotheses are that 1) left handers are at a disadvantage in a right handed world, 2) discrimination, possibly related to the cultural view of left handedness being a sign of evil, and 3) left handers will avoid manual labor jobs where the penalty for being left handed would be larger because tools are designed for right handed workers. For males, all three hypotheses are rejected by their data. Instead, they find that left handers, particularly those in manual labor jobs, earn a premium over right handers but that left handed females earn less than right handed females.

Reubeck, et al. (2007) also expect left handers to suffer a wage loss compared to otherwise identical right handed workers, for the same reasons given by Denny and O'Sullivan (2007). Their results also contradict that expectation, though they find that college educated left handed men earn more than similarly educated right handed men, and that the effect is largest for men with lower earnings levels compared to other men with similar levels of relatively high education. Their results include a weak finding of a higher wage for left handed laborers than for right handed laborers. They find no effect for women.

Both papers suffer from similar problems related to the identification of someone as left handed. For example, Denny and O'Sullivan (2007) count as left handed people who were 
reported to be so as seven year olds. The problem with this, as the authors note, is that children often use both hands at that age and become more one sided only later. The literature on lateralness has developed a continuous scale from right to left in recognition that most people do some activities with each hand. A second difficulty is that there may be unobservable traits for which handedness is merely a proxy. Coren (1995) identifies two cognitive styles, one which is better at using a body of knowledge to produce a known answer, and the other of which is better at extending understanding outside the existing knowledge. Left handedness is more prevalent among people who are better at the latter; that is, there is some evidence that left handers are more creative than right handers. Higher earnings for left handers could be the result of this greater creativity. Another possibility is that left handers make job or occupation choices differently than do right handers. In this case, left handedness is a proxy for the traits that lead to these different occupational choices, but without detailed occupation data the researchers cannot adequately control for occupational choice.

As is often the case with labor market issues, sports data may be able to shed light on some of these problems. Extensive data on production are connected directly to a specific worker and the industry context is nearly identical. Little has been done with sports data concerning the effects of lateralness on compensation and production. Bryson, Frick and Simmons (2009) considered the value to soccer players of being able to use both the right and the left foot; JC Bradbury (2006a,b), motivated by the appearance of the Denny and O'Sullivan (2007) and Reubeck, et al. (2007) papers, addressed the relationship of handedness and compensation of baseball players on his sabernomics blog.

While controlling for a variety of factors, Bradbury found no statistically significant difference between left-handed and right-handed batters, though the point estimate is for lefties 
to earn $\$ 225,000$ less than righties which is about $6 \%$ of the average batter's salary. Considering left versus right-handed pitchers, and controlling for innings pitched, the coefficient point estimate is $\$ 230,000$ for left-handed starters above right handed starters, but the effect is not statistically significant. However, left-handed relief pitchers are found to earn about $\$ 209,000$ less than right-handed relief pitchers, a result that is statistically significant. Bradbury points out a number of explanations for his results both for hitters and pitchers. For hitters he notes the lack of inclusion of defensive statistics and no control for lefties being excluded from some positions in the field. For pitchers, he notes there are no controls for relief pitchers known as "LOOGY" (Left-handed One Out GuY) and there are very few "ROOGY" types. Whatever the explanation for Bradbury's results, his findings are not consistent with those of Denny and O’Sullivan (2007) or Reubeck, et al. (2007) of premiums for left-handed workers.

Bryson, Frick, and Simmons (2009) considered whether soccer players who are adept players with both feet are compensated better than players who have a decidedly stronger side. They find pay premiums for two-footedness, and that the premium is largest for midfielders, and indeed may not exist for either defenders or forwards once performance, goal scoring, is accounted for. They conjecture that forwards, whose purpose is to score, get compensated for that but not for the other contributions to team success that two-footedness of midfielders provides. They do not examine whether goal scoring differentials exist among forwards based on footedness.

This paper looks at handedness as a potential determinant of compensation in hockey. An interesting phenomenon in ice hockey is that right-handed players tend to shoot left-handed while left-handed players tend to shoot right-handed. The explanation for this is that players tend to hold the end of the stick with their dominant hand. This means they will tend to have 
better control of the stick when reaching with it but their off hand will be in the middle of the stick when they go to shoot, and it is this hand that swings the stick. This phenomenon is apparent in the data, as the proportion of players that shoot left handed is far larger than the proportion of left handed people in the population. $^{2}$

The rest of this paper is organized into three sections. In the next section, part two, we look at means of salary, goals, and assists to determine if there are any differences by handedness among these variables. There are, and these differences lead to an exploration of the determinants of salaries in part three. Part four summarizes our findings.

2) Preliminary look at the data

We have a large database of players in the NHL and a similarly large database of players in the top Swedish professional ice hockey league. The NHL database was provided by Neil Longley and was used by Leo Kahane, Neil Longley, and Rob Simmons in their study of coworker heterogeneity and firm output (Kahane, Longley, and Simmons, forthcoming). The Swedish data was collected for players of the highest division, Elitserien, in Sweden from http://stats.swehockey.se/. Each data set covers a number of years and includes information of the position played, whether the player shoots right or left-handed, the number of goals scored, assists, and penalty minutes for each player. The NHL data also includes annual salary. For the Swedish sample, salary information is sparse, but it is available for the 2002-03 season and for

\footnotetext{
${ }^{2}$ Estimates of left-handedness vary from about $10 \%$ to $30 \%$, with the proportion apparently on the rise. In the NHL, $65 \%$ of players shoot left handed. In the Elitserien the proportion is $79 \%$.
} 
2005 or 2006 for a number of players. ${ }^{3}$ The NHL sample includes 3219 player-years; the Swedish sample 4201 player-years.

Using these two datasets, and following the evidence in the broader literature, we look for salary differences between right and left handed shooting hockey players. Table 1 shows difference in means salaries of right and left handed shooters by position in the NHL. On average, right and left handed shooters are paid the same in the full sample and looking only at those playing center. However, right and left handers are paid significantly differently on the wing positions, with pay higher for the right handers on the left wing and for left handers on the right wing. That raises the question of whether right handers are paid differently between the left and right wing positions, and similarly if left handers are paid differently between the left and the right wings. The mean salary of left handed shooters on the right wing is $\$ 2.53$ million while the salary of lefties on the left wing is $\$ 1.52$ million; right handed shooters on the right wing are paid $\$ 1.64$ million but right handed shooters on the left wing earn, on average, $\$ 1.88$ million. The difference for the left handed shooters is quite striking, over a million dollars per season between playing on the left and right wings, but even the nearly $\$ 200,000$ difference found for right versus left wing right handed shooters is quite impressive. For the lefties, the difference is statistically significant at the 0.0000 level; the difference for righties is statistically significant

\footnotetext{
${ }^{3}$ Unlike the NHL, the salaries of players in Elitserien are not public. Using Swedish Internal Revenue Service, Swedish newspapers have on two occasions published hockey and other Swedish professional sports salaries. The salary information for 2002 and 2005/2006 was collected from the Swedish newspapers Aftonbladet (http://www.aftonbladet.se/sportbladet/hockey/sverige/elitserien/article10417116.ab) and Expressen(http://extra.expressen.se/pdf/samycket.pdf). The income does not include the parts that are placed in pension funds. Some players are listed as having no salary which would occur if they did not receive payment for play or if they were playing abroad and did not pay taxes in Sweden.
} 
only at the 0.0951 level. The mean salary of a left handed shooter at the center position is $\$ 2.02$ million, for a right handed center the mean is $\$ 2.07$ million. The difference between a leftie on the right wing and a leftie at center, about half a million dollars, is statistically significant at the 0.001 level.

That these differences are significant at all is curious. If one is a left handed shooter, then playing any position other than on the right wing costs you a large amount of money, between a $\$ 0.5$ and $\$ 1.0$ million a year. Not all left handed shooters can play on the right wing, but discrepancies of this size between playing on the right and playing on the left or in the center raise questions about the existence of efficiency gains from reallocating players across positions. ${ }^{4}$

Before drawing any conclusions about the presence of inefficiencies, it is important to consider whether players on the right, left or in the center are more productive, where we take that to mean produce more goals, or more assists, than other players. To assess this, the first step is a series of difference of means tests in which the average goals by right-handed shooters are compared to average goals by left-handed shooters, both regardless of position played and according to position played. Table 2 shows the means for right handed and left handed shooters separately and the p-value for the difference in means test. The results for the NHL are on the left, the results for the Swedish league on the right. Note that the Swedish data identifies defensemen by left or right defense, something the NHL data does not do.

\footnotetext{
${ }^{4}$ Mason and Foster (2007) discuss the possibilities of "Moneyball on Ice", that is, that there is some player input into winning hockey that the hockey world incorrectly values, but all the possibilities discussed involve highly complex data collection and analysis. The beauty and power of the Moneyball hypothesis is that the mispriced attribute was easily observable.
} 
The first section of the table reports means and p-values simply comparing right and left handed shooters, without controlling for position. In both leagues, on average, right handed shooters score more goals and more goals per game played than do left handed shooters. In each league, the right handers score a bit over one more goal than do the left handers, and that translates into about 0.014 and 0.028 goals per game in the NHL and Elitserien, respectively. Why this difference occurs is unclear.

Splitting the players by position, the puzzle gets more complex. There is no statistically significant difference in average goals by right versus left handed shooting centers, in either league, but the goals per game averages are significantly different in both leagues. As in the full sample of players, right handed shooting centers score more goals per game than do left handed shooting centers. The difference in goals per game is actually slightly larger than in the full sample in both leagues. Comparing right and left handed shooting right and left wings, the results for the NHL players and the Elitserien players diverge. Average goals and goals per game are both significantly different between right and left handed shooting right wingers in the NHL, but they are not different for players from the Swedish league. Moreover, average goals and average goals per game are, for the first time, significantly larger for the left handed shooters than for the right handed shooters. In other words, a left handed shooting right winger in the NHL scores on average both more goals and more goals per game than does a right handed shooting right winger. Looking at left wingers, the opposite is true. Right handed shooting left wingers score both more goals and more goals per game played, on average, than left handed shooting right wingers. Interestingly, this is also true both in Sweden and in the NHL.

The Swedish data also splits defensemen into right and left defenders, though the NHL data does not. Admittedly, defenders are not expected to be prolific goal scorers. Nonetheless, 
right handed shooting defenders score more goals and more goals per game, on average, than do left handed shooting defenders, whether their position is left or right defensemen.

For the centers and right and left wingers, the attacking players, the metric for success must be goals scored. For defenders, goals are less important measures of accomplishment and the mean goals scored by defenders is quite a bit smaller than it is for centers and wings.

An alternative measure of success is assists; the ability to make a pass of the puck to a player in a good position to shoot and score. Conducting the same difference in means tests as for goals and goals per game, produces similar results as for those variables. Right handed shooters produce more assists, in Sweden, and more assists per game in both the NHL and Elitserien, than left handed shooters. Splitting by position, the difference in means tests show that right handed left wingers produce more assists on average than left handed left wingers in both leagues, though the difference is only significant at the $10 \%$ level for the Elitserien. For right wingers, left handed shooters produce more assists on average than do right handed shooters. These results carry over to assists per game, where the differences are significant at the $5 \%$ level or better in each case, with right handers on the left wing and left handers on the right wing producing better than lefties on the left or righties on the right. Right and left handed centers in the NHL do not produce on average a different number of assists, though right handed centers produce more assists per game than do lefties. In Sweden, left handed centers produce both more assists on average and more assists per game than do right handed centers. These differences are statistically significant at the $10 \%$ level (p-values are about 0.058 and 0.052 in the two cases, respectively. Right handed defenders produce statistically significantly more assists and more assists per game than left handed defenders, regardless of whether they are right or left defensemen. A table of these results is available upon request. 
The evidence on production is quite strong that left and right handed shooters are not equally productive, either in terms of goals or assists. This finding is particularly interesting for players on the wings, because lefties on the right are more productive than righties on the right, while righties on the left are more productive than lefties on the left. Given differential productivity, and the differential in compensation demonstrated above, the next question is whether those differences indicate mispricing of left handed versus right handed shooters. To address this issue we turn next to salary regressions.

3) Salary determination and returns to handedness

Sports economists have long studied the connection between player compensation and player production. Gerald Scully (1974) did this for Major League Baseball and found that the reserve system in place at the time his data was drawn from led to substantial underpayment of star players relative to their contributions to team success. Studies of salary determination in the NHL are also numerous (Jones and Walsh, 1988; Jones, et al., 1997, 1999; Idson and Kahane, 2000; Richardson, 2000; Lavoie, 2000; Longley, 1995; McLean and Veall, 1992; Lambrino and Ashman, 2007). Many of these are focused on discrimination, particularly discrimination against French-Canadians, or the role of violence in compensation. Kahane, Longley and Simmons (forthcoming) accounts for composition of the club by national origin and Idson and Kahane (2000) control for the performance of teammates in affecting one's own performance and, therefore, one's salary.

Estimating equations in these papers generally explain the natural logarithm of player salary with an array of player and team attributes, with focus on different attributes depending on 
the research question. The usual model will include goals and assists per game, or points per game $^{5}$, penalty minutes per game, player age and age squared, and player position. Height and weight of the player are included, along with the square of each. The data we use also include time on the ice per game and "plus/minus" per game. The plus/minus statistic awards a player a +1 if he is on the ice when his team scores an even-handed goal, that is, when both teams have the same number of players on the ice when the goal is scored, and a -1 if his team gives up an even handed goal.

Table 3 reports three fixed effects regression of log salaries using all players except goal keepers for the NHL seasons 2001 through 2007. The regressions all include team fixed effects and season dummies that are not reported. The results indicate that more points per game and more time on the ice lead to a higher salary. More penalty minutes lead to increased salary. Idson and Kahane (2000) and Haisken-Denew and Vorell (2008) also found more penalty minutes associated with greater pay. Idson and Kahane (2000) argued that more penalty minutes may proxy for more aggressive play, perhaps greater hustle, and determination, as well as willingness to make the sacrifices needed for team success. While this may be true, it is also the case that more penalty minutes leaves a team at a disadvantage and therefore less likely to win which is detrimental to team revenues. Coates, Battre, and Deutscher (2011) find that more penalty minutes may reduce team points (wins and ties) and are not connected to increased attendance. Actual fights statistically significantly reduce points. On the other hand, HaiskenDenew and Vorell (2008) find that the probability of a team advancing in the playoffs increases with penalty minutes and fights. However, Coates, et al. (2011) also find weak evidence that more penalty minutes are associated with greater revenues in the NHL. The positive coefficient

\footnotetext{
${ }^{5}$ Here points equal twice the number of goals plus the number of assists. If one simply adds goals and assists, the coefficient on points per game rises by about $50 \%$ but nothing else changes.
} 
on penalty minutes is consistent with the Idson and Kahane (2000) explanation, but given the Coates, et al. (2011) evidence, this may be evidence of mispricing in NHL compensation.

The results here also find a lower plus/minus score raises salary. This means that the more goals a team gives up, and the fewer it scores, when a player is on the ice the more that player is paid. The negative coefficient would possibly make sense if the variable included time on the ice killing penalties. However, it is calculated only for time when the teams are at equal strength. Consequently, the negative sign is an anomaly. Idson and Kahane (2000) find a positive coefficient, as would be expected.

Salary increases with age, but at a decreasing rate, and does the same with height. Increased weight reduces salary and does so at an increasing rate. ${ }^{6}$ The results indicate that offensive players, wingers and centers, are paid more than defenders, ranging between 22 and $29 \%$ boosts. Idson and Kahane (2000) found that forwards were paid less than defenders, by about 14 to $15 \%$. Idson and Kahane (2000) did not differentiate by forward position, as has been done here. Moreover, their salary data covers two seasons, in 1990-91 and 1991-92, but their explanatory variables are for the player's entire career up to the season for which the salary data is available. The data here is contemporaneous with the salary. More importantly, players switch positions over time, with equally large numbers of them moving from forward to defense or defense to forward. Later regressions reported below describe results when position switching is accounted for in the salary equation.

The second regression adds variables interacting being a left handed shooter with the three position dummy variables, and includes the left handed shooter dummy separately. This

\footnotetext{
${ }^{6}$ Little changes if the body mass index and BMI squared replace the height and weight variables.
} 
latter variable captures a salary increment for left handed shooting defensemen over right handed shooting defensemen, indicating there is a statistically significant boost of about $6.8 \%$. Left wingers that shoot left handed make significantly less than right handed shooting defensemen, all else constant. Left handed shooting right wings and centers are not paid differently than right handed defensemen.

The final regression adds interactions between points per game and the positionhandedness dummy variables. Each of these latter variables is statistically significant at the $5 \%$ level or better, and two of them are so at the $1 \%$ level or better. Each of them is positive indicating that a left handed shooter gets more compensation for points per game than a right handed shooter, all else equal. The coefficient on left handed shooting right winger points is nearly twice as large as those on left handed shooting left winger or center points. However, one cannot reject the null hypothesis that the three coefficients are equal. These results indicate that left handed shooting offensive players get compensated for each point they score at a higher rate than do right handed defensemen. Perhaps defensemen are not the right basis of comparison.

Table 4 reports the results of estimations using only centers and wingers. The first set of results show the impact of points per game, penalty minutes per game, time on the ice, plus/minus, height and weight, and position. As in the full sample, points, penalty minutes and time on the ice positively affect salary, and plus/minus is statistically significant but of the opposite sign than expected. Height and weight also affect salary in the same way as in the full sample. These results suggest that left wings are paid somewhat less than centers and right wings. 
The second and third set of results in the table add the left handed shooter - position interaction variables and the interactions of those variables with points per game. Without the interactions with points per game, it is clear that there is a slight boost to pay for being a left handed shooting center. Left handed shooting left wings clearly are paid substantially less than other offensive players; the coefficient implies a salary loss of $21 \%$ relative to right handed centers. That differential jumps to nearly $25 \%$ with the inclusion of the interaction with points per game. As before, there is no impact on the compensation for points of being a left handed shooter on the left side, but there is a large increment to being a left handed shooter on the right side of nearly $24 \%$.

These results suggest that left handed shooters have an incentive to switch to the right wing position. We looked at the data for evidence of position switches. In the data there are 40 switches from the left to the right wing, 29 of them by right handed shooting players, and 50 switches from center to the right wing, 35 of them by right handers. There are also 44 switches from the right to the left wing, 37 of them by left handed shooters, and 47 moves from center to left wing, 40 by left handers. The most common switches in the data are from one of the three offensive positions to defense, 229 in total with 163 of them by left handed shooting players, or from defense to offense also with 229 of them 151 of whom are left handers.

Table 5 reports regression results including variables identifying position switchers. These results indicate player moves are generally contrary to the financial interests of the movers. In fact, adding dummy variables for moves from right to left wing, left to right wing, center to left wing, center to right wing, right wing to center, left wing to center, and offense to 
defense into the salary regressions producing more support for this. ${ }^{7}$ The coefficients on right to left, right to center and offense to defense are each negative and statistically significant at the 5\% level or better. Left to center is negative and significant at the $10 \%$ level. The point estimates of the other coefficients on position switching variables are all negative though not individually significant. This means that players who switch positions earn lower compensation than players who stick with one position.

\section{Conclusion}

Previous work on the impact of handedness on compensation has been general rather than focused on professional athletes. The evidence there was that left handers get slightly higher earnings than right handers. Here, looking at professional hockey players, there is evidence that players that shoot left handed are paid more than players that shoot right handed. It is important to note that many right handed players shoot left handed, and many left handed players shoot right handed. Further exploration shows that the effects are largely limited to left handed shooters playing the right wing position. The analysis held constant time on the ice, penalty minutes, player size, the quality of the players on the ice with the individual, and team and season. There is, therefore, a puzzle. Why would players be compensated differently for scoring points for their team based on their handedness?

One has to wonder also whether players and team officials know about this differential. It seems unlikely that players do because if they did it would seem likely that large numbers of left handed shooting centers and left wingers would clamor to play on the right wing where

\footnotetext{
${ }^{7}$ Adding a dummy variable for defense to offense position switches has no effect on the other results and while the point estimate of the coefficient is negative, it is not statistically significant.
} 
compensation is so much greater. Instead, the evidence here is that players move the wrong way, away from the more highly compensated positions. Moreover, switching positions of any type in this data is associated with salary reductions or, at best, no effect on compensation. Point estimates indicate movers whose pay changes take lower pay by between 16 and 19\% compared to players who do not switch or position switchers whose pay is not statistically significantly lower.

None of the analysis done here is conclusive for inefficiency in the allocation of playing talent. Nonetheless, the fairly substantial pay differentials which arise from playing the same position but shooting with a different hand even after accounting for playing time and points per game are suggestive of a labor market inefficiency. The finding that points scored by left handed shooting players on the right wing are compensated differently than points scored by other players suggests inefficiency as well. Unlike the esoteric search for a mispriced playing attribute being undertaken inside hockey as described by Mason and Foster (2007), and quite similar to the mispricing of on-base-percentage made famous in Moneyball, and this inefficiency, should it stand up to further scrutiny, is easy to observe. 


\section{References}

Altonji, Joseph G. and Rebecca M. Blank. (1999). "Race and Gender in the Labor Market," in Handbook of Labor Economics, volume 3c. Amsterdam, New York, and Oxford: Elsevier Science, North Holland.

Annett, Marian and Margaret Manning. (1989) "The Disadvantages of Dextrality for Intelligence," British Journal of Psychology, 80(2):213-26.

Benbow, Camilla. (1986) "Physiological Correlates of Extreme Intellectual Precocity," Neuropsychologia, 24(5):719-25.

Biddle, Jeff E. and Daniel S. Hamermesh. (1994) "Beauty and the Labor Market," American Economic Review, 84(5):1174-94.

Bradbury, J.C. (2006a) "Do Southpaws get a fair shake in MLB?" http://www.sabernomics.com/sabernomics/index.php/2006/08/do-southpaws-get-a-fair-shake-in$\underline{\mathrm{mlb} /}$

Bradbury, J.C. (2006b) "Do Southpaws get a fair shake in MLB? Part 2: pitchers" http://www.sabernomics.com/sabernomics/index.php/2006/08/do-southpaws-get-a-fair-shake-in$\underline{\text { mlb-part-2-pitchers/ }}$

Bryson, Alex, Bernd Frick, and Rob Simmons. (2009) “The Returns to Scarce Talent: Footedness and Player Remuneration in European Soccer," CEP Discussion Paper No. 948.

Coates, Dennis, Marcel Battre and Christian Deutscher. (2011) "Does Violence Pay in Professional Hockey?: Cross Country Evidence from Three Leagues”, in Violence and Aggression in Sporting Contests, R. Todd Jewell, editor, Springer: New York.

Coren, Stanley. (1995) "Differences in divergent thinking as a function of handedness and sex," American Journal of Psychology, 108:311-325.

Denny, Kevin and Vincent O’Sullivan. (2007) “The Economic Consequences of Being LeftHanded: Some Sinister Results,” Journal of Human Resources, 42(2):353-374.

Heineck, Guido. (2005) "Up in the skies? The relationship between body height and earnings in Germany,” Labour, 19(3):469-489.

Hicks, Robert and Christine Dusek. (1980) “The Handedness Distributions of Gifted and NonGifted Children," Cortex, 16(3):479-81.

Idson, Todd and Leo Kahane. (2000) "Team Effects on Compensation: An Application to Salary Determination in the National Hockey League," Economic Inquiry, 38(2):345-357. 
Jones, J. C. H., \& Walsh, W. D. (1988). "Salary determination in the National Hockey League: The effects of skills, franchise characteristics, and discrimination," Industrial and Labor Relations Review, 41(4), 592-604.

Jones, J. C. H., Nadeau, S., \& Walsh, W.D. (1997). “The wages of sin: Employment and salary effects of violence," Atlantic Economic Journal, 25(2), 191-206.

Jones, J. C. H., Serge Nadeau, and William D. Walsh. (1999) "Ethnicity, Productivity and Salary: Player Compensation and Discrimination in the National Hockey League," Applied Economics, 31(5): 593-608.

Kahane, Leo, Neil Longley, and Robert Simmons (forthcoming, 2012) "The Effects of Coworker Heterogeneity on Firm-Level Output: Assessing the Impacts of Cultural and Language Diversity in the National Hockey League," Review of Economics and Statistics.

Lambrinos, James and Thomas D. Ashman. (2007) "Salary Determination in the NHL: Is Arbitration Efficient?," Journal of Sports Economics, 8(2):192-201.

Lavoie, Marc (2000) “The Location of Pay Discrimination in the National Hockey League," Journal of Sports Economics, 1(4): 401-11.

Longley, Neil. (1995) "Salary Discrimination in the National Hockey League: The Effects of Team Location," Canadian Public Policy, 21(4): 413-22.

Lewis, Michael. (2003) Moneyball: The Art of Winning an Unfair Game. W.W. Norton and Company.

Mason, Daniel S. and William M. Foster. (2007) "Putting Moneyball on Ice," International Journal of Sport Finance, 2:206-213.

McLean, Robert C. and Michael R. Veall (1992) "Performance and Salary Differentials in the National Hockey League," Canadian Public Policy, 18(4): 470-75.

Reubeck, Christopher S., Joseph E. Harrington, Jr., and Robert Moffitt. (2007). "Handedness and Earnings," Laterality, 12(2):101-120.

Richardson, David. (2000) "Pay, Performance, and Competitive Balance in the National Hockey League," Eastern Economic Journal, 26(4):393-417.

Scully, Gerald. (1974) "Pay and Performance in Major League Baseball," American Economic Review, 64(6):915-930. 
Table 1: Difference of mean salaries NHL

\begin{tabular}{clll} 
& \multicolumn{1}{l}{ Right } & \multicolumn{1}{l}{ Left } & p-value \\
Salary & 1785682 & 1848398 & 0.3337 \\
& \multicolumn{3}{c}{ Center } \\
Salary & \multicolumn{3}{c}{ Right Wing } \\
\cline { 2 - 4 } & \multicolumn{3}{c}{0.6950} \\
Salary & 1638163 & 2531296 & 0.0000 \\
& \multicolumn{3}{|c}{ Left Wing } \\
Salary & 1882105 & 1523797 & 0.0428
\end{tabular}


Table 2: Difference of mean goals scored by position and shooting hand

\begin{tabular}{|c|c|c|c|c|c|c|}
\hline & Right & Left & $\mathrm{p}$-value & Right & Left & $p$-value \\
\hline & \multicolumn{3}{|c|}{ NHL } & \multicolumn{3}{|c|}{ Sweden } \\
\hline goals & 12.03 & 10.93 & 0.0011 & 5.974 & 4.798 & 0.0000 \\
\hline goals per game & 0.1675 & 0.1533 & 0.0013 & 0.1271 & 0.0989 & 0.0000 \\
\hline \multirow[t]{2}{*}{ observations } & 1111 & 2126 & & 885 & 3316 & \\
\hline & \multicolumn{6}{|c|}{ Center } \\
\hline goals & 14.9269 & 14.0034 & 0.1557 & 8.022 & 7.398 & 0.3342 \\
\hline goals per game & 0.2108 & 0.1933 & 0.0323 & 0.1803 & 0.1502 & 0.0143 \\
\hline \multirow[t]{2}{*}{ observations } & 260 & 573 & & 134 & 600 & \\
\hline & \multicolumn{6}{|c|}{ Right Wing } \\
\hline goals & 15.0505 & 19.4792 & 0.0000 & 6.917 & 7.5029 & 0.2773 \\
\hline goals per game & 0.2075 & 0.2749 & 0.0000 & 0.1542 & 0.1562 & 0.8489 \\
\hline \multirow[t]{2}{*}{ observations } & 217 & 416 & & 253 & 511 & \\
\hline & \multicolumn{6}{|c|}{ Left Wing } \\
\hline goals & 17.8675 & 14.5808 & 0.0069 & 8.6058 & 7.0944 & 0.0179 \\
\hline goals per game & 0.2398 & 0.2043 & 0.0215 & 0.1689 & 0.1444 & 0.0393 \\
\hline \multirow[t]{2}{*}{ Observations } & 83 & 501 & & 137 & 646 & \\
\hline & & & & \multicolumn{3}{|c|}{ Right Defense } \\
\hline goals & & & & 3.3756 & 2.6434 & 0.0102 \\
\hline goals per game & & & & 0.073 & 0.0546 & 0.0010 \\
\hline \multirow[t]{2}{*}{ Observations } & & & & 213 & 516 & \\
\hline & & & & \multicolumn{3}{|c|}{ Left Defense } \\
\hline goals & & & & 4.4554 & 2.6976 & 0.0000 \\
\hline goals per game & & & & 0.0842 & 0.0586 & 0.0010 \\
\hline Observations & & & & 101 & 625 & \\
\hline
\end{tabular}


Table 3: Log Salary Fixed Effects Regressions - variables per game where relevant

Points

Penalty min

Age

Age Sq.

Height

Height Sq.

Weight

Weight Sq.

Time on ice

Plus/Minus

Right Wing

Left Wing

Center

Shoots Left

Shoots Left*Left Wing

Shoots Left*Right Wing

Shoots Left*Center

Shoots Left*Left Wing*Points

Shoots Left*Right Wing*Points

Shoots Left*Center*Points

Constant

Team fixed

Season

$\begin{array}{ccl}\text { Basic Model } & \\ & & \text { p- } \\ \text { Coeff. } & \text { Std.Err. } & \text { value } \\ 0.6334 & 0.0424 & 0.0000 \\ 0.0850 & 0.0195 & 0.0000 \\ 0.2247 & 0.0223 & 0.0000 \\ -0.0028 & 0.0004 & 0.0000 \\ 0.5449 & 0.2658 & 0.0400 \\ -0.0036 & 0.0018 & 0.0480 \\ -0.0253 & 0.0149 & 0.0900 \\ 0.0001 & 0.0000 & 0.0490 \\ 0.0899 & 0.0040 & 0.0000 \\ -0.1436 & 0.0590 & 0.0150 \\ 0.2260 & 0.0405 & 0.0000 \\ 0.2033 & 0.0409 & 0.0000 \\ 0.2513 & 0.0376 & 0.0000\end{array}$

Shoots Left $*$ Position

$\mathrm{p}$ -

Coeff. Std.Err. value

$\begin{array}{lll}0.6340 & 0.0425 & 0.0000\end{array}$

$\begin{array}{lll}0.0937 & 0.0195 & 0.0000\end{array}$

$\begin{array}{lll}0.2246 & 0.0222 & 0.0000\end{array}$

$\begin{array}{lll}-0.0028 & 0.0004 & 0.0000\end{array}$

$\begin{array}{lll}0.6042 & 0.2660 & 0.0230\end{array}$

$\begin{array}{lll}-0.0040 & 0.0018 & 0.0280\end{array}$

$\begin{array}{lll}-0.0221 & 0.0149 & 0.1380\end{array}$

$\begin{array}{lll}0.0001 & 0.0000 & 0.0790\end{array}$

$\begin{array}{lll}0.0890 & 0.0039 & 0.0000\end{array}$

$\begin{array}{lll}-0.1439 & 0.0589 & 0.0150\end{array}$

$\begin{array}{lll}0.2438 & 0.0473 & 0.0000\end{array}$

$\begin{array}{lll}0.3833 & 0.0692 & 0.0000\end{array}$

$\begin{array}{lll}0.2310 & 0.0504 & 0.0000\end{array}$

$\begin{array}{lll}0.0658 & 0.0324 & 0.0420\end{array}$

$\begin{array}{lll}-\mathbf{0 . 2 2 5 0} & 0.0686 & 0.0010\end{array}$

$\begin{array}{lll}0.0092 & 0.0539 & 0.8640\end{array}$

0.0301

0.0501

0.5480
Shoots left * position

*Points

p-

Coeff. Std.Err. value

$\begin{array}{lll}0.5167 & 0.0524 & 0.0000\end{array}$

$\begin{array}{lll}0.0922 & 0.0196 & 0.0000\end{array}$

$\begin{array}{lll}0.2237 & 0.0222 & 0.0000\end{array}$

$\begin{array}{lll}-0.0028 & 0.0004 & 0.0000\end{array}$

$\begin{array}{lll}0.5671 & 0.2658 & 0.0330\end{array}$

$\begin{array}{lll}-0.0037 & 0.0018 & 0.0400\end{array}$

$\begin{array}{lll}-0.0215 & 0.0149 & 0.1500\end{array}$

$\begin{array}{lll}0.0001 & 0.0000 & 0.0880\end{array}$

$\begin{array}{lll}0.0906 & 0.0040 & 0.0000\end{array}$

$\begin{array}{lll}-0.1509 & 0.0588 & 0.0100\end{array}$

$\begin{array}{lll}0.2860 & 0.0485 & 0.0000\end{array}$

$\begin{array}{lll}0.4386 & 0.0705 & 0.0000\end{array}$

$\begin{array}{lll}0.2801 & 0.0519 & 0.0000\end{array}$

$\begin{array}{lll}0.0614 & 0.0323 & 0.0570\end{array}$

$\mathbf{- 0 . 3 5 1 2} 0.0846 \quad 0.0000$

$\mathbf{- 0 . 2 5 4 8} 0.0986 \quad 0.0100$

$\begin{array}{lll}-0.0929 & 0.0691 & 0.1790\end{array}$

$\begin{array}{lll}0.1753 & 0.0709 & 0.0130\end{array}$

$\begin{array}{lll}0.3196 & 0.0946 & 0.0010\end{array}$

$\begin{array}{lll}0.1713 & 0.0665 & 0.0100\end{array}$

$\begin{array}{lllllllll}-10526.3 & 1418.1 & 0.0000 & -10495.7 & 1416.6 & 0.0000 & -10438.8 & 1414.7 & 0.0000\end{array}$

Yes

Yes

Yes
Yes

Yes

Yes 
Table 4: Log salary regressions - offensive players only
Basic Model

Points

Penalty min

Age

Age Sq.

Height

Height Sq.

Weight

Weight Sq.

Time on ice

Plus/Minus

Right Wing

Left Wing

Shoots Left

Shoots Left*Left Wing

Shoots Left*Left Wing*Points

Shoots Left*Right Wing*Points

Constant
Shoots Left*Right Wing

$\begin{array}{rrl}\text { Coeff. } & \text { Std.Err. } & \text { value } \\ 0.7650 & 0.0582 & 0.0000 \\ 0.0910 & 0.0241 & 0.0000 \\ 0.2208 & 0.0285 & 0.0000 \\ -0.0028 & 0.0005 & 0.0000 \\ 0.5680 & 0.3499 & 0.1050 \\ -0.0038 & 0.0024 & 0.1170 \\ -0.0310 & 0.0178 & 0.0820 \\ 0.0001 & 0.0000 & 0.0570 \\ 0.0831 & 0.0063 & 0.0000 \\ -0.3446 & 0.0828 & 0.0000 \\ -0.0278 & 0.0277 & 0.3170 \\ -0.0497 & 0.0284 & 0.0800\end{array}$

$\begin{array}{rrrr}\mathbf{0 . 0 8 9 0} & \mathbf{0 . 0 3 8 9} & \mathbf{0 . 0 2 2 0} \\ \mathbf{- 0 . 2 4 1 1} & \mathbf{0 . 0 7 3 0} & \mathbf{0 . 0 0 1 0} \\ -0.0262 & 0.0591 & 0.6580\end{array}$

Shoots Left * position

Coeff. Std.Err. $\quad$ value

$\begin{array}{lll}0.7635 & 0.0581 & 0.0000\end{array}$

$\begin{array}{lll}0.0987 & 0.0242 & 0.0000\end{array}$

$\begin{array}{lll}0.2221 & 0.0285 & 0.0000\end{array}$

$\begin{array}{llll}-0.0028 & 0.0005 & 0.0000\end{array}$

$\begin{array}{llll}0.6362 & 0.3507 & 0.0700\end{array}$

$\begin{array}{lll}-0.0042 & 0.0024 & 0.0790\end{array}$

$\begin{array}{lll}-0.0275 & 0.0178 & 0.1240\end{array}$

$\begin{array}{llll}0.0001 & 0.0000 & 0.0880\end{array}$

$\begin{array}{lll}0.0821 & 0.0063 & 0.0000\end{array}$

$\begin{array}{lll}-0.3404 & 0.0826 & 0.0000\end{array}$

$\begin{array}{llll}0.0092 & 0.0416 & 0.8250\end{array}$

$\begin{array}{lll}0.1394 & 0.0653 & 0.0330\end{array}$

$\begin{array}{lll}\mathbf{- 0 . 2 4 1 1} & 0.0730 & 0.0010\end{array}$ $\begin{array}{lll}-10511.5 & 1815.7 & 0.0000\end{array}$

$-10577.0$

$1815.3 \quad 0.0000$
Shoots left $*$ position $*$ points

Coeff. Std.Err. p-value

$\begin{array}{lll}0.7221 & 0.0619 & 0.0000\end{array}$

$\begin{array}{lll}0.1010 & 0.0242 & 0.0000\end{array}$

$\begin{array}{lll}0.2186 & 0.0285 & 0.0000\end{array}$

$\begin{array}{lll}-0.0027 & 0.0005 & 0.0000\end{array}$

$\begin{array}{lll}0.6041 & 0.3508 & 0.0850\end{array}$

$\begin{array}{lll}-0.0040 & 0.0024 & 0.0960\end{array}$

$\begin{array}{lll}-0.0269 & 0.0179 & 0.1340\end{array}$

$\begin{array}{lll}0.0001 & 0.0000 & 0.0960\end{array}$

$\begin{array}{lll}0.0826 & 0.0063 & 0.0000\end{array}$

$\begin{array}{lll}-0.3433 & 0.0826 & 0.0000\end{array}$

$\begin{array}{lll}0.0064 & 0.0416 & 0.8780\end{array}$

$\begin{array}{lll}0.1414 & 0.0652 & 0.0300\end{array}$

$\begin{array}{lll}0.0878 & 0.0389 & 0.0240\end{array}$

$\begin{array}{lll}-0.2852 & 0.0887 & 0.0010\end{array}$

$\begin{array}{lll}\mathbf{- 0 . 2 1 1 7} & 0.1016 & 0.0370\end{array}$

$\begin{array}{lll}0.0611 & 0.0713 & 0.3910\end{array}$

$\begin{array}{lll}0.2144 & 0.0946 & 0.0230\end{array}$

$\begin{array}{lll}-10346.7 & 1816.7 & 0.0000\end{array}$
Team fixed

Season
Yes

Yes
Yes

Yes
Yes

Yes 
Table 5: Log Salary Regression - position switching

Points

Penalty min

Age

Age Sq.

Height

Height Sq.

Weight

Weight Sq.

Time on ice

Plus/Minus

Right Wing

Left Wing

Center

Shoots Left

Shoots Left*Left Wing

Shoots Left*Right Wing

Shoots Left*Center

Shoots Left*Left Wing*Points

Shoots Left*Right Wing*Points

Right Wing to Left Wing

Left Wing to Right Wing

Center to Left Wing

Center to Right Wing

Right Wing to Center

Left Wing to Center

Offense to Defense

Constant
Coeff. Std.Err. p-value

$\begin{array}{lll}0.5498 & 0.0552 & 0.0000\end{array}$

$\begin{array}{lll}0.0921 & 0.0195 & 0.0000\end{array}$

$\begin{array}{lll}0.2100 & 0.0223 & 0.0000\end{array}$

$\begin{array}{lll}-0.0026 & 0.0004 & 0.0000\end{array}$

$\begin{array}{lll}0.5289 & 0.2651 & 0.0460\end{array}$

$\begin{array}{lll}-0.0035 & 0.0018 & 0.0560\end{array}$

$\begin{array}{lll}-0.0191 & 0.0149 & 0.1990\end{array}$

$\begin{array}{lll}0.0001 & 0.0000 & 0.1190\end{array}$

$\begin{array}{lll}0.0876 & 0.0039 & 0.0000\end{array}$

$\begin{array}{lll}-0.1446 & 0.0586 & 0.0140\end{array}$

$\begin{array}{lll}0.2307 & 0.0498 & 0.0000\end{array}$

$\begin{array}{lll}0.3898 & 0.0716 & 0.0000\end{array}$

$\begin{array}{lll}0.2386 & 0.0529 & 0.0000\end{array}$

$\begin{array}{lll}0.0275 & 0.0384 & 0.4740\end{array}$

$\begin{array}{lll}-0.2691 & 0.0716 & 0.0000\end{array}$

$\begin{array}{lll}-0.2097 & 0.0967 & 0.0300\end{array}$

$\begin{array}{lll}-0.0118 & 0.0539 & 0.8260\end{array}$

$\begin{array}{lll}0.1042 & 0.0567 & 0.0660\end{array}$

$\begin{array}{lll}0.1998 & 0.0934 & 0.0320\end{array}$

$\begin{array}{lll}\mathbf{- 0 . 1 8 4 0} & 0.0796 & 0.0210\end{array}$

$\begin{array}{lll}-0.0648 & 0.0834 & 0.4370\end{array}$

$\begin{array}{lll}-0.0205 & 0.0772 & 0.7910\end{array}$

$\begin{array}{lll}-0.0346 & 0.0757 & 0.6470\end{array}$

$\begin{array}{lll}\mathbf{- 0 . 1 9 2 6} & \mathbf{0 . 0 7 8 8} & \mathbf{0 . 0 1 5 0}\end{array}$

$\begin{array}{lll}-0.1453 & 0.0773 & 0.0600\end{array}$

$\begin{array}{lll}\mathbf{- 0 . 2 0 8 5} & \mathbf{0 . 0 3 9 3} & \mathbf{0 . 0 0 0 0}\end{array}$

$\begin{array}{lll}-10.2436 & 8.9385 & 0.2520\end{array}$

Team fixed

Yes

Season

Yes 
